\title{
LE FILS NATUREL (1757), DE DIDEROT, O LA ESPECTACULARIDAD DE UNA «CONDITION» JURÍDICO-FAMILIAR
}

\author{
José Calvo González \\ Universidad de Málaga
}

RESUMEN. Estudio interdisciplinario de «Derecho y Literatura» sobre Le fils nature/ con análisis de la categoría dramática y jurídica de "condition». Referencia a la posición jurídica del «hijo natural» en el derecho francés de la época y el Code civil, así como al valor de su espectacularidad escénica en la teoría del drama burgués diderotiano, y posterior excursus jurídico-literario en Honoré BALZAC y Alejandro DUMAS (hijo).

Palabras clave: derecho y literatura, teatro, Denis DIDEROT, nuevo «contrato social» y derecho de familia, relaciones paterno-filiales.

\section{Diderot's Le Fils naturel (1757), or the spectacularity of a juridical «condition» of family}

ABSTRACT. Interdisciplinary Study of «Law and Literature» on Le fils nature/ with analysis dramatic and legal category of «condition». Reference to the legal position of «natural son» in French law of the time and the Civil code, as well as the value of its spectacular scenic in the Diderot's theory of bourgeois drama, and subsequent legal-literary excursus Honoré BALZAC and Alexander DUMAS (son).

Keywords: law and literature, theatre, Denis DIDEROT, new «social contract» and family law, parent-child relationship.

\footnotetext{
* Fecha de recepción: 14 de mayo de 2014. Fecha de aceptación: 12 de junio de 2014.
} 
¡Cuántos incidentes importantes pueden sacarse del asunto más sencillo, si se tiene la paciencia de meditar! ¡Qué color puede dárseles cuando se es elocuente! No se es poeta dramático sin ser elocuente. ¿Y pensáis acaso que careceré de espectáculo? ${ }^{1}$

Denis Diderot, La paradoja del comediante

\section{EL ESPACIO ESCÉNICO COMO ESPECTÁCULO EN DIDEROT}

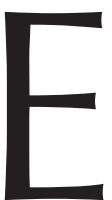

1 modo de concebir la escena que fue propio del teatro europeo durante el siglo XVII y la primera mitad del XVIII dista mucho del ideado por Denis DIDEROT (1713-1784) en el último tercio de esa misma centuria. En casi todo lo relacionado con el espectáculo escénico, que a lo largo del siglo XVII apenas había logrado más que un desarrollo rudimentario y pobre, es ciertamente posible advertir una profunda renovación a partir de finales del siglo XVIII, por entero perceptible ya desde inicios del siglo XIX. Sin embargo, no creo que la experimentación escenográfica introducida por DIDEROT haya actuado como preparatoria de esa mudanza. La razón estribaría, pienso, en la muy diferente comprensión conceptual de la espectacularidad que autores, dueños de compañías teatrales y comediantes tuvieron a la base del diseño escénico en cada uno de esos momentos y periodos.

El tramo final del siglo XVIII y consecutivo hacia el XIX organizó la noción de espectáculo teatral a través fundamentalmente del reclamo de la puesta en escena. Los espectadores de esa etapa se sintieron particularmente atraídos por la novedad escenográfica que en las maniobras de tramoya les ofrecían mutaciones físicas y transformaciones mecánicas capaces de producir ante sus ojos admirables ilusiones espaciales y asombrosos efectos especiales, y así también quedaron fascinados por todo el rico attrezzo que en conjunto les entregaba la visión de la pintura de telones, del decorado, la iluminación y el vestuario ${ }^{2}$. Nada de esto hallaremos en el espectáculo teatral diderotiano. A diferencia de aquellas escenografías donde lo espectacular era el ingenio del aparato, y a veces directamente lo aparatoso, el montaje y proceso escénico en las creaciones dramáticas de DIDEROT presenta una espectacularidad sencilla, natural, espontánea, que no incide en lo visible para potenciarlo hasta el pasmo y la maravilla, sólo impresionando córnea y pupila, sino que entrevé y pone a la vista lo invisible permitiendo acceder a su contemplación intelectual, es decir, que enfoca a la retina interior y profunda, dándolo al ojo de la inteligencia. Si para otros el espectáculo fue una forma de visión de lo extraordinario, el espectáculo en DIDEROT miró a mostrar la invisibilidad de lo ordinario. A mi juicio, DiDEROT está aquí más cerca del sentido ideal y función primigenia de spectacŭlum — poner a la vista y visibilizar- que todos sus contemporáneos y que muchos de los escenógrafos del tiempo sucesivo.

Que esta clase de espectacularidad constituía un experimento visual innovador no es dudoso y es además poco discutible, aunque hoy pueda quizá resultar difícil su comprensión ideológica. Lo estorba, a riesgo incluso de impedirlo, la desvirtuación que la socie-

\footnotetext{
1 DIDEROT, 1920: 66.

2 Gaiffe, 1910; MélÈse, 1934; Lough, 1957; Lagrave, 1972; Carlson, 1972; Fried, 1980; Hays, 1981; MitTMAN, 1984; RAVEL, 1993, 1999.
} 
dad tardo y posmoderna ha introducido en el concepto de spectacŭlum, ya alertada por Marshall MCLUHAN (1964) en la remisión al piélago de imágenes en que a diario se baña nuestra conciencia ${ }^{3}$, mediación luego denunciada por Guy DEBORD (1967) como impostura y farsa especular, junto a social también política, que todo lo presenta del revés, más tarde asimismo puntualizada como artificio cultural y simulacro estético en la categoría hiperreal de lo «inmediático» y en la representación delusoria por Jean BAUDRILLARD (1977, 1978, 1987), acaso diagnosticada en su penúltima fase como fútil y volátil moral de civilización todavía recientemente por Mario VARGAS Llosa (2008, 2009, 2012).

Es por todo ello, evitando más innecesarios detalles en el recorrido que traza la perversión del concepto de spectacŭlum, que al proponer la idea de espacio escénico como espectáculo en DIDEROT tampoco me parece que haya existido —o, más allá de cierto teatro modernista y de avant-garde, yo no la descubro- recuperación escenográfica diderotiana con el siglo Xx, y menos posible se me hace creer que exista alguna semejanza significativa con aquélla entre los escenográfos del presente.

Los medios con que en el espacio escénico DiDEROT construye el espectáculo de las relaciones entre obra y espectador son dos, y ambos visuales. Uno consiste en la adopción de un punto de vista que no recurre al theatrum para producir sentido de verdad por proximidad con el espectador, verosimilitud realista ${ }^{4}$. Otro es la semiología gestual, o pantomima.

Punto de vista es, a mi parecer, la unidad visual del tableau (DIDEROT, 2008: 128) o lo que es igual, el encuadre de un espectáculo cotidiano que escenifica el fresco de la vida real visibilizando la «fisonomía» estética, ética, social y política de una época. El punto de vista que ofrece el tableau es así lo bastante atrayente ${ }^{6}$ y de exuberante realismo como para no precisar de artificios formales y materiales, esto es, de recursos representativos que mediante lances teatrales (coups de théâtre) de plasticidad objetual o posicional más o menos forzada y «tramposa» prefiguren, o refiguren, el dispositivo de la posición desde la que el espectador observa. El tableau enmarca una visión privilegiada donde el espectador puede observarse en el lugar del espectáculo, y así identificarse con la visión de lo que allí se ofrece a la expectación. El contenido de esa espectacularidad coincide con el lugar ocupado por el espectador, es decir, lo incluye, y más simbólicamente se coordina a una constelación sociológica (SzONDI, 1979) de costumbres en la escena de la vida civil -la vie civile, tableau de moeurs, tableaux vivants - articulada en la lógica de la clase burguesa y circunstanciada en su conciencia

3 MCLuChan, 1964; McLuchan y Fiore, 1967.

4 El logro de la verosimilitud realista en el drama burgués tiene lugar por alejamiento de la fantasía de irreales ficciones. «Que el argumento sea importante y la intriga sencilla, doméstica y vecina a la vida real» y «es muy conveniente presentar a los hombres tal como son. Aquello que deberían ser es algo demasiado sistemático y vago para servir de fundamento a un arte de imitación [...] ¿Qué es verdad? La conformidad de nuestros juicios con los seres. ¿Qué es la belleza de imitación? La conformidad de la imagen con la cosa», escribe en Conversaciones sobre «El bijo natural (DIDEROT, 2008: 171, 191). En lo demás, DIDEROT igualmente transfundirá este verismo de la estética teatral a la poética narrativa, como ha establecido Hans Robert JAUSS por comparativa receptiva (Rezeptionsästhetik) entre Entretiens sur le Fils Naturel (1757) y Eloge de Richarson (1762) (JAUSS, 1969: 157-178).

5 Es conocida la analogía pictórica con que DIDEROT construye su concepto: «Una disposición de esos personajes en el escenario, tan natural y verdadera que, plasmada fielmente por un pintor, me agradara sobre una tela, es un cuadro» (DIDEROT, 2008: 128).

6 «Cuanto más se ve un buen cuadro, más gusta» (DIDEROT, 2008: 172). 
de clase media y situaciones cotidianas y domésticas. Pero lo que la espectacularidad organiza es mucho más que una exhibición de registros epocales sobre el costumbrismo burgués; instituye una sociología realista de la moral burguesa y una teoría materialista de su determinación histórico-social. De esta manera, la ideación del espacio escénico como espectáculo en DIDEROT logrará hacer visible — aquí está la paradoja, en realidad su consecuencia dialéctica - no una microestructura de vida, sino propiamente una macroestructura de vida.

En cuanto a la novedosa y afortunada ${ }^{7}$ integración escénica de la semiología del gesto a través de la pantomime, aun cuando ésta no implique una abolición del discurso $^{8}$, supone no obstante un expediente también sobre todo de naturaleza visual, pues espectacularizaba una «fisonomía» sensorial — corporeizada, carnalizada— de las emociones y pasiones, a distancia de las proferencias textuales, que resultan silenciadas, o con ínfimo apoyo en ellas ${ }^{9}$. Al introducir en escena la retórica del gesto — signa et indicia faciat motus atque sensus sui- se interpela al ojo anímico del espectador; la mímica de la expresión facial ensaya una petitio reactiva (serenidad, deleite, asombro, contracción, contrición, misericordia, dolor, llanto...) frente al observador, quien se identifica activamente con las emociones que ve escenificadas.

Por último, pantomime y tableau —expresión visual y expresión corporal—interactúan escénicamente ${ }^{10}$.

\section{EL ESPECTÁCULO «DES CONDITIONS»}

La lógica espectacular de todo el sistema dramático diderotiano, basada en la fórmula «imiter la nature», plantea la cuestión, difícilmente eludible, de la paradoja. La

7 «La pantomima, tan desatendida entre nosotros, es utilizada en esta escena, y usted mismo ha experimentado con qué éxito» (DIDEROT, 2008: 137).

8 FrantZ, 1998: 25; MorTIER, 1997, e IDA, 1999. En específico sobre pantomima en Le Neveu de Rameau acúdase a RAETHER, 1987; y HEARTZ, 1989.

9 Conocido es, por cuanto abiertamente confesado por el propio DIDEROT en Lettre sur les sourds et les muets (1751), su hábito en alejarse del escenario buscando con ese distanciamiento obtener la perspectiva del conjunto de las varias acciones dramáticas, y de aplicar «sordina» a los parlamentos: «Je fréquentais jadis beaucoup les spectacles, et je savais par coeur la plupart de nos bonnes pièces. Les jours que je me proposais un examen des mouvements et du geste, j’allais aux troisièmes loges; car plus j’étais éloigné des acteurs, mieux j'étais placé. Aussitôt que la toile était levée, et le moment venu où tous les autres spectateurs se disposaient à écouter, moi, je me mettais mes doigts dans mes oreilles non sans quelque étonnement de la part de ceux qui m'environnaient, et qui, ne me comprenant pas, me regardaient presque comme un insensé qui ne venait à la comédie que pour ne la pas entendre. Je m'embarrassais fort peu des jugements et je me tenais opiniâtrement les oreilles bouchées, tant que l'action et le jeu de l'acteur me paraissaient d'accord avec le discours que je me rappelais. Je n'écoutais que quand j'étais dérouté par les gestes, ou que je croyais l'être. Ab! Monsieur, qu'il y a peu de comédiens en état de soutenir une pareille épreuve, et que les détails dans lesquels je pourrais entrer seraient bumiliants pour la plupart d'entre eux. Mais j'aime mieux vous parler de la nouvelle surprise où l'on ne manquait pas de tomber autour de moi lorsqu'on me voyait répandre des larmes dans les endroits pathétiques, et toujours les oreilles bouchées. Alors on n'y tenait plus, et les moins curieux hasardaient des questions auxquelles je répondais froidement "que chacun avait sa façon d'écouter et que la mienne était de me boucher les oreilles pour mieux entendre”; riant en moi-même des propos que ma bizarrerie apparente ou réelle occasionnait, et bien plus encore de la simplicité de quelques jeunes gens qui se mettaient aussi les doigts dans les oreilles pour entendre à ma façon, et qui étaient tout étonnés que cela ne leur réussît pas» (DIDEROT, 1969-1973: II, 532).

10 «Hay que ocuparse en serio de la pantomima, abandonar los lances teatrales cuyo efecto es momentáneo y encontrar cuadros» (DIDEROT, 2008: 172). 
paradoja del comediante (1773) suscita en efecto el contrasentido actoral de la imitación impostada; el verismo ha de ser únicamente interpretativo, el verismo ha de ser siempre la interpretación de una naturaleza puramente ideal ${ }^{11}$. Ello debería implicar que no cupiera desanudar la lógica espectacular de los límites de la expectativa, y sin embargo aquí deviene la paradoja, pues lo que el comediante entrega al espectáculo del observador como innatural, es decir una no-copia de «las cosas tal como son en la Naturaleza», se recibe en éste con expectativa naturalidad. En esa desconexión abunda asimismo una vez que habiendo dejado establecido «no mostrar al espectador un hecho sin verosimilitud», además distingue entre las acciones verosímiles «las que hay que exponer a la vista de las que hay que dejar entre bastidores» (DIDEROT, 1920: 31, 81). Con todo, no será sólo esta paradoja del comediante, bien conocida y estudiada ${ }^{12}$, la que hallemos, ni de la única que convenga tratar.

Está, igualmente, la paradoja del espectador. Así DiDEROT también desagrega la lógica espectacular respecto de los límites de la expectativa cuando en su sistema dramático introduce, como sucede en Le neveu de Rameau (1762) ${ }^{13}$, que no todo aquello de lo que es posible ser espectador ha de convertirse en espectáculo; es decir, des-espectaculariza la expectación. Y todavía quizá otro nivel paradójico aún más profundo, donde nuevamente lógica espectacular y límites de la expectativa se disocian para generar la paradoja del espectáculo sin espectadores. Y es que, tan cierto como paradójico, DiDEROT logra a través de la disipación del público la apoteosis verista del espectáculo; v. gr., el Prologue a Le Fils naturel: «Dorval, que había alejado a todos, me colocó en un rincón, desde el cual, sin ser visto, vi y oí» (DiDEROT, 2008: 46).

Ahora bien, si la lógica espectacular de DIDEROT abarca toda esta tan miscelánea dimensión paradójica, en ningún momento, sin embargo, anula la existencia del límite de la expectativa del observador del espectáculo, que debe prevalecer como principio, incluso si múltiplemente excepcionado. El sistema dramático diderotiano mantiene así como postulado inquebrantable, rigurosamente coherente además, que el espectáculo nunca ha de ser aquello que el espectador no pueda ver porque esté más allá de sus límites de expectativa. Entonces la fundamental cuestión acerca de la lógica espectacular consistirá, por tanto, en interrogarse y responder sobre lo que no es ajeno al espectador, o sea, lo que entra dentro de los límites de su expectativa. Pero tan importante como ello será no inadvertir que si éstos pueden localizarse en un punto de vista muy cercano al observador, también pueden hallarse situados - aun sin exceder el in focus - a una mucha mayor distancia de aquél, y que por tanto el problema será asimismo de profundidad de campo, es decir, de relación entre los puntos más próxi-

11 «Reflexionad un momento sobre eso que llaman en el teatro ser natural. ¿Es acaso el mostrar las cosas tal como son en la Naturaleza? En manera alguna. Lo natural, en este sentido, no sería más que la vulgaridad. ¿Qué es, pues, la naturalidad escénica? Simplemente, la conformidad de las acciones, del discurso, del rostro, de la voz, del ademán, del gesto, con un modelo ideal imaginado por el poeta y a menudo exagerado por el comediante. He ahí lo maravilloso. Ese modelo no sólo influye en el tono, sino que modifica hasta el paso, hasta el aspecto. De aquí que el comediante en la calle y en la escena sea dos personajes tan distintos que cuesta trabajo reconocerlos». Y también: «Aquel, pues, que mejor conoce y con más perfección expresa esos signos exteriores, con arreglo al modelo ideal mejor concebido, es el gran comediante» (DIDEROT, 1920: 31, 81).

12 Dieckmann, 1969; y Fried, 1980: 1.35.

13 Diderot, 1985. 
mos y más lejanos que forman el área de encuadre, al cabo responsables de la nitidez de la expectativa.

Sentado lo anterior, creo que in focus del espectáculo es, fuera de toda duda, la familia burguesa. La lógica espectacular de tal decisión constituye, además, un ejercicio de autoafirmación del espectador en sus límites de expectativa. DIDEROT espectaculariza aquello que de ningún modo es ajeno al espectador en su ineludible condition de parte integrante de un álbum de familia.

El foco de expectativa del tableau, proyectado desde el constructo teatral diderotiano de la condition, actúa a favor de algún tipo de expectación familiar reconocible. Otra cualquier posible variación del punto de vista está subordinada, esto es, supeditada, y por ende limitada, a producir únicamente un efecto de expectativa que ha de ser sólo accesorio respecto de lo principal.

[...] no son los caracteres lo que hay que llevar a escena, sino las condiciones. Hasta ahora, en la comedia el carácter ha sido el objeto principal y la condición sólo el accesorio; la condición debe convertirse en la actualidad en el objeto principal y quedarse el carácter en accesorio [...] Lo que debe servir de fundamento a la obra es la condición, sus deberes, sus ventajas e inconvenientes. [...] Por poco recargado que estuviera un carácter, un espectador podría decirse a sí mismo: ese no soy yo. Pero no puede negar que el estado que se interpreta ante él no sea el suyo: no puede ignorar sus deberes. Debe aplicarse totalmente lo que oye.

$\mathrm{Y}$ a las objeciones de novedad arguye:

«Me parece que ya se han tratado algunos de esos asuntos».

No es así, no se lleve usted a engaño.

« ¿Acaso no tenemos financieros en nuestras piezas?».

Seguramente los hay, pero el financiero no está hecho.

«Gustaría encontrar una sin un padre de familia».

De acuerdo, pero el padre de familia no está hecho. En una palabra, me gustaría saber si los deberes de las condiciones, sus ventajas, sus inconvenientes y sus riesgos se han llevado a la escena. Si son el fundamento de la intriga y de la moral de esas piezas. Luego, si esos deberes, esas ventajas, esos inconvenientes y esos riesgos no nos muestran a diario a los hombres en situaciones muy difíciles.

«Así, usted quisiera que se interpretara al literato, al filósofo, al comerciante, al juez, al abogado, al político, al ciudadano, al magistrado, al financiero, al gran señor, al intendente».

Añádales todas las relaciones: el padre de familia, el esposo, la hermana, los hermanos. ¡El padre de familia! ¡Qué argumento para un siglo como el nuestro, donde parece que no se tenga ni la más remota idea de lo que sea un padre de familia!

Piense que a diario se crean condiciones nuevas. Piense que tal vez nada nos es menos conocido que las condiciones y debería interesarnos más. Cada cual tiene su estado en la sociedad pero tenemos que tratar con gente de todos los estados.

¡Las condiciones! ¡Cuántos detalles importantes, cuántas acciones públicas y domésticas, verdades desconocidas, situaciones nuevas que sacar de ese fondo! (DIDEROT, 2008: 185).

La espectacularidad del tableau diderotiano traduciría esa gama pictórica des conditions en piezas que van desde Le Fils naturel, ou Les Éprewves de la vertu, la que aquí me ocupa, a Le Père de famille (1758) — «C'est la vocation générale de tous les hommes»—y finalmente Est-il bon? Est-il méchant (1775-1784). 


\section{DERECHO Y LITERATURA: LA «CONDITION» JURÍDICO-FAMILIAR COMO «CONDITION» DRAMÁTICA}

Le Fils naturel es el primer caso concreto de «condition» dramática elaborada por DIDEROT, donde además aprovecha para anunciar el proyecto, seguramente ya en avanzada escritura, de lo que será Le Père de famille: « $i$ Qué hermoso argumento el del padre de familia!... Es la vocación general de todos los hombres» (DIDEROT, 2008: 204).

La investigación de las posibilidades dramáticas de la «condition» arranca en DIDEROT del deseo de renovar categorías teatrales que, como sucede con la del caractère, a su juicio desequilibraban — por aligerar o, con más frecuencia, sobrecargar- la relación entre el espectador y el personaje. En ese objetivo DIDEROT acude a la noción de status, en la que a partir de cualidades y elementos de naturaleza abstracta depurará situaciones comunicables — «cada cual tiene su estado en la sociedad pero tenemos que tratar con gente de todos los Estados»- capaces de subsumir algún punto de vista típico. El personaje resulta así tipificado, convertido en personaje-tipo, y para esa tipicidad o tipología regular y abstracta no halla mejor nominal que «condition».

Ahora bien, al explorar una eventual concurrencia entre derecho y el teatro diderotiano a partir del enclave «condition» hemos de asumir cierta dificultad lingüística. Porque es cierto que en la lengua francesa de la época esta forma léxica remite a un significado cuyo campo empleo acoge además de naturaleza, estado o cualidad de una persona o cosa, sea por su índole intrínseca o por relación a su nacimiento $(v$. gr.: être de grande condition), asimismo lo referido a la profesión o estado al que se pertenece (v. gr.: chacun doit vivre selon sa condition $)^{14}$, y ninguna acepción sin embargo que incumba a derecho; esto es, en tanto que expresiva de una condition juridique. No obstante, aunque tal uso de la voz «condition» no encontrara registro oficial de significado en el Dictionnaire de l'Académie françoise, es indiscutible que —al tiempo de DIDEROT tanto como hoy - toda y cualquier apelación de sintaxis jurídico-cultural a conditio iuris (condition juridique) no podría remitir y equivaler sino a legal position, legal status, posizione giuridica, Rechtsstellung, o lo que es igual, al statut juridique o cadre juridique, de donde cabría entender por condition juridique lo específicamente definido como la situation o manera de ser o estar de cada uno relativamente a una institución jurídica (situation juridique abstraite) o a una regla de derecho (situation juridique spécifique) ${ }^{15}$, siendo pues perfectamente razonable conceder que al hablar de la «condition» de pa-

14 Dictionnaire de l'Académie françoise (1772: I, 253). Esta edición sigue la cuarta, de 1762.

15 «La noción de situación jurídica [...] corresponde a la manera de ser de cada uno frente a una institución jurídica determinada. Los términos de situación jurídica, que durante un largo tiempo no eran de uso corriente, en la actualidad son empleados a cada paso, pero en algunas ocasiones en un sentido vago o aún en un sentido muy diverso. En realidad, estos términos son susceptibles de dos sentidos [...]; un sentido abstracto y un sentido concreto, o, dicho de otra manera, se distingue la situación jurídica abstracta y la situación jurídica concreta $[. .$.$] Se entiende por situación jurídica abstracta la manera de ser eventual o teórica de cada uno con$ respecto a una institución determinada. Desde el momento en que una institución jurídica es organizada, engendra, en efecto, de pleno derecho, una o varias situaciones jurídicas abstractas. Supongamos que una ley reorganiza el derecho de sucesiones y viene a crear diversas categorías que no existían antes; todos aquellos que reúnan las condiciones fijadas por la ley a este efecto, adquieren la calidad, la situación jurídica de causahabientes, pero es sólo una citación jurídica abstracta, desprovista de todo alcance positivo hasta la apertura de la sucesión a la cual se refiere [...] en virtud de la aplicación de las reglas de derecho y de las instituciones jurídicas, [...] las situaciones jurídicas pasan de lo abstracto a lo concreto»; BONNECASE, 1931; BONNECASE, 2000: 55-56. 
dre de familia, o hijo natural, no se excluyera lo incorporado ideológicamente por la noción de una condition juridique o situation juridique. Y es así que, efectivamente, DIDEROT lo incorporaba, como lo incorporará también la doctrina científica del derecho desde finales del siglo XIX ${ }^{16}$.

En Le Fils naturel, con miras a la elaboración general de la categoría dramática de «condition» capaz de contener una como la de padre de familia, DiDEROT nos habla de los deberes, ventajas e inconvenientes en que a diario se muestra a los hombres en tales situaciones, las que nunca antes se han llevado a la escena, y menciona relaciones derivadas de ello («el padre de familia, el esposo, la hermana, los hermanos»), y lo hace también en orden concretamente a la filiación refiriendo «ciertas obligaciones». Ello revela en mi opinión que el núcleo irradiante de todo ese universo referencial se halla integrado por el derecho de familia.

Abunda este parecer lo esgrimido por el propio DIDEROT en De la poésie dramatique (1771) para defensa contra la acusación de plagio lanzada por el crítico ÉlieCatherine FRÉRON (1719-1776) ${ }^{17}$ tras darse a conocer en 1758 la traducción francesa de Il Vero amico, obra del dramaturgo italiano Carlo GOLDONI (1707-1793) ${ }^{18}$. DiDEROT recurre allí a un argumento de derecho de familia como es el estado jurídico de la filiación ilegítima y al contexto de vínculos fraterno-familiares por vía paterno-lineal:

la naissance illégitime de Dorval est la base du Fils naturel. Sans cette circonstance, la fuite de son père aux îles reste sans fondement. Dorval ne peut ignorer qu'il a une soeur et qu'il vit à côté d'elle (DIDEROT, 1969-1973: III, 445).

En consecuencia, si aceptamos esta propuesta interpretativa el paso inmediato habría de ser admitir a su vez la posibilidad de que el juego innovador de la «condition» dramática del fils naturel incluya asimismo la voluntad de renovar la categoría de condition juridique o situation juridique del derecho de familia vigente $\mathrm{y}$, por consiguiente, inaugurar en su seno respecto de aquél un diferente statut o cadre juridique que como nueva relación depure en su caractère lo principal de lo accesorio.

Desde luego, ésta ha sido la línea en que viene pronunciándose la crítica literaria con regularidad para en ese sentido señalar cómo las obras teatrales francesas de mitad en adelante el siglo XVIII trasladan una manifiesta mejora socio-literario hacia la bastardía, además destacando de modo muy preciso a Le Fils naturel como el punto de inflexión decisivo para el reexamen del tema de la filiación ilegítima ${ }^{19}$. A diferencia del teatro renacentista y su significada «peinture comique de la bâtardise» (CORNEILLE, RACINE), que sólo desempeña algún protagonismo tratándose enrevesadas intrigas y está expuesta con figuración grotesca o degenerada, los dramaturgos - y también novelistas- de la ilustración rescatan el color dramático de su sacrificio y disponen sobre el escenario, espectacularizan, el injusto estigma de su alma ${ }^{20}$. Plantean con ello una

16 Vid., entre otros, Richard, 1866; Blache, 1879; Fontaine, 1881; Coulon, 1887; AugÉE y Dorlhac, 1891; Regnault, 1922; Cariciente Benacerraf, 1951; Barbarin, 1960; Dabin, 1965; Savatier, 1965; VAn HONSTÉ, 1977.

17 BALCOU, 1973.

18 GOLDONI, 1758. Si bien venía atribuyéndose la traducción a M. DELEYRE, hoy parece, sin embargo, ya plenamente establecida para VÉRON DE FORBONNAIS.

19 Baudin, 1932: 59-67; Fellows, 1981; Armand, 2011: 41-45.

20 Diderot insistirá con variantes del tema en los diálogos de Le Neveu de Rameau y también en la novela La Religieuse (c. 1780). Destacan igualmente BEAUMARCHAIS con Le Mariage de Figaro (1784), o BERNARDIN DE 
perspectiva de crítica social donde se visibilizan los prejuicios morales y religiosos que acerca del deseo sexual y la licitud de las relaciones extramaritales están en la base de la condition juridique de la ilegitimidad en la institución de la filiación natural ${ }^{21}$.

Los instrumentos con que el drama burgués opera esta transformación de la expectativa del observador son dos diversamente documentados. Sin duda el mejor conocido de ellos, la estima por el esprit sensible, cuya patética de nuevo valor estético constituye igualmente la ética virtuosa del bonnête homme. En efecto, el teatro de filósofos aborda la oscura y triste suerte del fils naturel espectacularizando a la luz deconstructora de las candilejas escénicas la exaltación de su virtud ${ }^{22}$; una virtud de valor y dolor sacrificial, que llevada al grado de máxima generosidad de entrega, de renunciación ${ }^{23}$, como sucede con el Dorval, incluso puede inmolar en el ara de la amistad la pasión y hasta el amor ${ }^{24}$.

Pero ya sabemos también que entre 1760 y finales de siglo ese théâtre bourgeois fue asimismo théatre révolutionnaire; desde luego lo era en el caso de DIDEROT ${ }^{25}$. Y tan ciertamente importante como haber examinado y valorado la cultura política que le sirvió de trasfondo ${ }^{26}$ y lo que de éste vendría a primer plano en un devenir muy próximo, ha de ser igualmente el estudio y la evaluación en torno a la no renuncia a perfilar la línea de un horizonte jurídicamente reinstituyente. Esto nos sitúa ante la segunda de las herramientas utilizadas en la transformación de la expectativa del observador en el drama burgués, menos desarrollada que la anterior.

A mi juicio el théâtre des conditions buscó refundar la condition juridique des bâtards, de los hijos ilegítimos, o cuando menos su sustancial mejora. La novedad de la «condition» dramática está pues, según lo entiendo, en no ocultar una vocación refundadora de la vigente condition juridique sobre filiación como parte de un nuevo «contrato social» para el derecho de familia.

A este respecto, la reinterpretación de las convenciones morales socialmente dominantes para redimir al fils naturel del abandono y la soledad ${ }^{27}$, tal como va propuesta

SAINT-Pierre con Paul et Virginie (1788). Vid. por extenso en BAUdin, 1932: 117-122. Asimismo en relación a obras narrativas, ROBERT, 1972, 1994; HUNT, 1994, y FOWLER, 2000: 38-63, 64-92 y 113-144, para, respectivamente, Le Fils naturel, Le Neveu de Rameau y La Religieuse.

21 EDMisTON, 1985: 99.

22 LEWINTER, 1966. También MAUZI, 1961, y más en general MAUZI, 1960.

23 «Il n'en deviendra pas amoureux; et il ne sera plus le rival de son ami» (DIDEROT, 1969-1973: III, 445).

24 «Queridos y bárbaros deberes! Amistad que me encadena y me desgarra: serás obedecida. Oh, virtud, ¿qué eres si no exiges algún sacrificio? Amistad, sólo eres un nombre hueco si no impones alguna ley... ¡Clairville casará con Rosalía!» (DIDEROT, 2008: 87).

25 MÉNIL, 1995; STENGER, 2013.

26 Vid. FeILla, 2013: 65-90.

27 Conciencia ésta, por lo demás, no muy extendida ni aun entre los propios filósofos. D'ALEMBERT hace excepción en su Portrait de l'auteur fait par lui-même, et adressé, en 1760 a Mme ${ }^{* * * *}$. Así, al escribir: «Sans famille et sans liens d'aucune espèce, abandonné de très bonne heure à lui-même, accoutumé dès son enfance à un genre de vie obscur et étroit, mais libre, né, par bonbeur pour lui, avec quelques talents et peu de passions, il a trouvé dans l'étude et dans sa gaieté naturelle une ressource contre le délaissement où il était; il s'est fait une sorte d'existence dans le monde sans le secours de qui que ce soit, et même sans trop chercher à se la faire. Comme il ne doit rien qu'à lui-même et à la nature, il ignore la bassesse, le manège, l'art si nécessaire de faire sa cour pour arriver à la fortune. Son mépris pour les noms et pour les titres est si grand, qu'il a eu l'imprudence de l'afficher dans un de ses écrits, ce qui lui a fait, dans cette classe d'hommes orgueilleux et puissants, un assez grand nombre d'ennemis qui voudraient le faire passer pour le plus vain de tous les hommes; mais il n'est que fier et indépendant, plus porté d'ailleurs à s'apprécier au-dessous qu'au-dessus de ce qu'il vaut» (D'AlEMBERT, 1821-1822: I, 11). 
en el teatro de «condiciones», sin duda cursa con otros textos ${ }^{28}$, y en particular con Entretien d'un père avec ses enfants ou Du danger de se mettre au-dessus des lois (1771$1773)^{29}$, que son expresivos de la tensión renegociadora ${ }^{30}$ entre ley y justicia, entre los valores jurídicos formales y la fuerza anterior e instituyente, fuerza legítima que todo lo puede, fuerza que es la de «l'homme de bien» y el «tribunal de l'équité naturelle» ${ }^{31}$. Pero es en Le Fils naturel y sus Entretien donde hallamos el primer pronunciamiento de argumentos destinados a articular, en clave de lege ferenda, de pedagogía al legislador, los principios jurídico-morales habilitadores de la reintegración familiar y la pretensión de tendencia hacia una nuevo equilibrio jurídico, de mayor simetría e incluso de simetría reforzado, para el futuro de las relaciones paterno-filiales.

El primero de ellos ha venido teniendo una lectura de amplísima repercusión respecto al deterioro - hasta la enemistad más profunda - de las relaciones personales e ideológicas entre DiDEROT y ROUSSEAU ${ }^{32}$. Pienso, no obstante, que es también posible su inserción en el contexto de la «condition» dramática del fils naturel, lo que apuntaría al propósito de refundar la condition juridique des bâtards. DIDEROT escribe (acto IV, escena iii):

Ha recibido los más infrecuentes talentos y se debe a la sociedad [...] ¡Renunciar a la sociedad! Apelo a su corazón: pregúntele y le dirá que el hombre de bien vive en sociedad y que únicamente el malvado está solo (DIDEROT, 2008: 95).

A mi parecer el texto puede traslucir una conexión entre vida privada (conciencia moral) y deberes públicos como base renegociadora del «contrato social familiar», con ofrecimiento de reintegración a la «sociedad familiar». Tal sentido cabe desprenderlo desde un doble prisma interpretativo; porque la interlocutora de Dorval es en ese fragmento Costanza, cuyo discurso asume allí claramente un rol paternal, y asimismo porque la finalidad es refutar el proscripción social de Dorval en su condición de fils naturel. Costanza incardina a Dorval desde la expulsión y exilio: «L'homme de bien est dans la société, et qu'il n'y a que le méchant qui soit seul» (DIDEROT, 1975: 82) al reingreso y entrada, vía familia, en el organismo social. El estatus social de Dorval es hasta entonces el de un outsider ${ }^{33}$. Por el contrario, ser miembro de una familia equivale a formar parte de la sociedad; el extrañamiento del orden social se impugna con la familia. Ésta sería la idea básica del nuevo «contrato familiar» en garantía jurídica de estabilidad social. No hemos de olvidar que entretanto, es decir durante l'Ancien régime, la condition juridique de Dorval continúa siendo la de «fils selon la nature, mais non selon le droit» (GOLZINK: 2000, 264).

Y está, al propio tiempo, la constatación de Dorval como fils naturel y sin embargo acreditado portador de los valores virtuosos del homme de bien, del honnête homme, lo que igualmente postula que la renegociación ha de tener como objetivo el logro de un replanteamiento del equilibrio familiar en las relaciones paterno-filiales, tendente a favorecer en la vida de familia una simetría reforzada por la proporcionalidad. El

\footnotetext{
28 DAVIES, 1991.

29 Diderot, 1969-1973: IX. Vid. también Chartier, 1997, 1998.

30 SIMON, 2001: 78-97.

31 DIDEROT, 1969-1973: IX, 76.

32 Rousseau, 1997: 597 y 617 y ss. Vid. también FABRE, 1961.

33 PUCCI, 2004.
} 
sentido de la ecuación, integrando elementos de manifiesta naturaleza jurídica —-tales como equilibrio, simetría y proporcionalidad - es enunciado por DIDEROT a las páginas finales de sus Entretiens en fórmula de concluyente redención reparadora: «Dorval morirá contento si puede merecer que digan de él, cuando ya no exista: "Su padre, que era un hombre muy honrado, no lo fue tanto como él”» (DiDEROT, 2008: 203).

La teoría espectacular de la «condition» dramática, pese a los no pocos momentos de desencanto ${ }^{34}$ — quizá incluso de desaliento- experimentado, y de las muchas dificultades ${ }^{35}$ que a su propugnador se opusieron, obtuvo, no obstante, un propicio eco jurídico. Aconteció durante la excitante y peligrosa etapa inmediata a los años de la Revolución. Los avatares de esa recepción en la condición jurídica de los bijos naturales ya han comenzado a ser reconstruidos ${ }^{36}$. La acogida inicial lo fue con oportunidad de la sustanciación de procedimientos que resolvieron a favor de la capacidad de los hijos ilegítimos para recibir asignaciones testamentarias, lo que aprovecharía a una construcción jurisprudencial evolutiva en la que aquéllos acabaron por encontrar acceso al orden sucesorio. Esto fue posible merced a la progresiva aceptación por los juristas franceses de la doctrina sobre derechos sucesorios en Samuel PUFENDORF (1632-1694) -De iure naturae et gentium (1672), Lib. III, Cap. I, \ ix-, quien no los desprendía de la ley natural ${ }^{37}$ sino del derecho civil, y así por tanto permitiendo que cada estado en particular pudiera determinar lo más conveniente a su interés público. Con antecedentes en autores que como Jean DOMAT (1625-1696) en Lois civiles dans leur ordre naturel (1689-1694) o Francois BOURJON (†1751) en Droit commun de la France (1747) habían secundado una concepción moderna de la ley natural de corte profano, y en especial a través de la doctrina científica de Robert-Joseph POTHIER (1699-1772) en Traité du contrat de mariage (1768), partidario de entender que el parentesco en las uniones ilegítimas no era únicamente natural, sino también de afinidad civil, se preparó el camino que en la cultura jurídica pre-revolucionaria abriría a la redefinición de la filiación natural, y a través de él al paulatino abandonó de los criterios que hasta entonces habían excluido a los hijos ilegítimos del orden sucesorio ${ }^{38}$. Creo que este desarrollo, salvo algún error no despreciable ${ }^{39}$, es importante, aunque sólo muy late-

34 En referencia específica a Le Père de famille (1758), pero en alusión a su teatro «des conditions», DIDEROT confiesa: «Porque no habiendo obtenido el éxito que me prometía, y sin grandes esperanzas de llegar a hacerlo mejor, me asqueé de una carrera para la cual no me juzgué con suficientes talentos» (DIDEROT, 1920: 75).

35 «Si no tuve éxito en un principio, fue porque el género era extraño a los espectadores y a los actores; porque había un perjuicio, que todavía subsiste, contra lo que llaman comedia llorona; porque tenía una nube de enemigos en la corte, en la ciudad, entre los magistrados, entre la gente de la iglesia, entre los hombres de letras [...] Verdad es que era del número de los que llaman filósofos, considerados entonces como ciudadanos peligrosos [...] Sin contar que esos filósofos habían hecho, en general, más difícil la misión de los poetas y literatos», DiDEROT, 1920: 76-77. Vid. asimismo CONNORS, 2012.

36 Vid. GERBER, 2005.

37 Vid. también Pufendorf, 1984: Lib. II, Cap. 3.

38 GERBER, 2005: 251-252.

39 GERBER, 2005: 256. GERBER acusa de tibieza a Antoine-Gaspar DE BOUCHER D’ArGis (1708-1791), uno de los juristas colaboradores de proyecto enciclopédico DIDEROT, por no criticar expresamente la injusticia de la discapacidad hereditaria de los hijos extramatrimoniales. Estimo que esta objeción, en la que hace partícipe a DIDEROT al redactar la voz «Loi naturelle (morale)» es, además de imprecisa, errónea. Así: a) recientes trabajos consideran como compilador probable de ésta voz a BOUCHER D’ARGIS antes que a DiDEROT; BURNS, 1984; $b$ ) el autor de la voz «Bâtard, ou Enfant naturel» es el abogado y escritor François-Vincent ToussAINT (1715-1772) (Diderot y D'AlemberT, 1751-1765: II, 138); c) BOUCHER D’ARGIS redacta la voz «Légitimation» (DIDEROT y D'AlemberT, 1751-1765: IX, 363, col. 2); d) la voz «Bâtards» subraya la carencia familiar — «ne sont d'aucune 
ralmente remarque el aporte del théâtre des conditions y omita la contribución derivada de otros escritos diderotianos referenciales, como las reflexiones a la traducción del Essai sur la merité et la vertu (1745), de Anthony ASHLEY-COOPER (1671-1713), tercer conde de Shaftesbury.

En todo caso, algo más tarde, ya en pleno periodo revolucionario, cuando apenas se habían cumplido unos años desde la muerte de DIDEROT, su fe en el progreso moral como resultado de la propagación de la razón moral ${ }^{40}$, donde a su vez se incluiría la convicción en el poder regenerativo del derecho, se vio satisfecha con la promulgación de una cadena de leyes civiles que acordaban el reconocimiento al fils naturel - si bien con excepción de los hijos adulterinos e incestuosos- del derecho a la sucesión sobre el patrimonio de sus padres naturales ${ }^{41}$.

Pero el telón de la Historia aún no había caído.

\section{4. ¡ABAJO EL TELÓN! DERECHO CONTRA LITERATURA: LE CODE CIVIL DE 1804}

«Son père, qui était si bonnête bomme, ne fut pas plus honnête qui lui», había escrito DiDEROT en busca de espectacularizar en la filiación natural de Dorval el horizonte en un nuevo contrato social para el derecho de familia, un nuevo orden en garantía de la estabilidad familiar [...] Le Fils naturel tuvo una fugaz existencia teatral, con sólo una representación, el año 1771. La de sus lecciones morales alcanzó, en todo caso, hasta la redacción del Code civil des Français de 1804, el Code civil napoléonien. Las raíces burguesas de éste ${ }^{42}$ ciertamente no arraigaron en el hondón de la cultura jurídica prerevolucionaria, y menos todavía en la revolucionaria. Sin embargo, en su decisión de des-reconocimiento de la familia natural no mostraba falta de interés en la estabilidad social. El Code empleó este mismo argumento, si bien perspicazmente reconducido; agudeza muy característica de los juristas. Sus redactores deseaban conjurar categóricamente las perturbaciones del orden social familiar, cuya amenaza veía representada — diríase que a partes iguales — en la filiación ilegítima y la investigación de la paternidad, y desde luego fueron contundentes en la respuesta.

Procés-verbaux du Conseil d'État. Séance du Conseil d'État, 26 brumaire an X (17 novembre 1801).

LE PREMIER CONSUL (Napoléon).

[...] L'intérêt de la société pourrait faire admettre la maxime contraire si elle devait produire des enfants légitimes; mais la société n'a pas intérêt à ce que des bâtards soient reconnus ${ }^{43}$.

La catarsis, la «purificación» técnica, ahora del todo reconstruida ${ }^{44}$, se organizó del siguiente modo:

\footnotetext{
famille»- de los hijos ilegítimos, y e) generalmente las voces de la Encyclopédie son descriptivas y raramente normativas.

40 EDMiston, 1985: 126.

41 Vid. Loi du 12 Brumaire An II, completada sucesivamente por Loi du 15 Thermidor An IV, Loi du 2 Ventôse An VI, y Décret du 2 Germinal An XI.

42 Arnaud, 1969, 1973; así como CARBonnier, 1981, 1986.

43 FENET, 1827-1828: X, 76-77.

44 Vid. SAADA, 2012; BLOQUET, 2012, y abundante bibliografía en ellos citada.
} 
Liv. Premier, Des personnes, Tit. VII, «De la paternité et de la filiation» (art. 321 à 342):

- Art. 338: «L'enfant naturel reconnu ne pourra réclamer les droits d'enfant légitime».

- Art. 340: «La recherche de paternité est interdit».

- Art. 342: «Qui défend la recherche d'une maternité adultérine (ou incestueuse), ne peut être opposé à l'enfant qui, en demandant à prouver qu'il est fils d'une femme mariée, se propose d'établir en sa faveur, non pas une filiation adultérine, mais une filiation légitime».

Liv. III, Des biens, et des différentes manières dont on acquiert la propriété, Tit. Ier. «Des Successions» (art. 7111 a 892):

- Art. 756: «Les enfants naturels ne sont point héritiers: la loi ne leur accorde de droit sur les biens de leur père ou mère décédés, que lorsqu'ils ont été légalement reconnus».

En consecuencia, el fils naturel es expulsado de la sociedad, destierro donde ni es posible la felicidad ni tampoco la moralidad. Y será sólo la literatura quien así lo denuncie. Está, por ejemplo, Antony, el drama en cinco actos de Alexandre DumAS (padre), estrenado en el teatro de la Porte Saint-Martin el 3 de mayo de 1831, aún en la turbiedad romántica de su defensa, pero cuya audible exclamación — «Adesso e sempre»- es inconfundible proclama de la exclusión y marginalidad de los hijos ilegítimos ${ }^{45}$. Más nítido, Le Fils naturel, comedia en cinco actos y prólogo de Alexandre Dumas (hijo), puesta en escena en el teatro del Gymnase-Dramatique de París el 16 de enero de 1858, que transparenta el afeamiento del autor con algunas actitudes de su propio padre, enuncia la obligación moral de todo progenitor con su prole y reclama la legitimación por subsiguiente matrimonio de los nacidos fuera de él ${ }^{46}$.

En cuanto a la narrativa, creo que bastará con referir Ursula Mirouët (1855), sobre las hereditarias de una hija natural, con acción ambientada en 1830, de Honoré DE BALZAC (1799-1850), para apreciar la crudeza de la ley civil en su aplicación por los Tribunales de la Nación:

La rigueur de la loi est si grande sur les droits des enfants naturels, dit le licencié de fraîche date jaloux de montrer son savoir, qu'aux termes d'un arrêt de la cour de cassation du 7 juillet 1817, l'enfant naturel ne peut rien réclamer de son aïeul naturel, pas même des aliments. Ainsi vous voyez qu'on a étendu la parenté de l'enfant naturel. La loi poursuit l'enfant naturel jusque dans sa descendance légitime, car elle suppose que les libéralités faites aux petits-enfants s'adressent au fils naturel par interposition de personne. Ceci résulte des articles 757, 908 et 911 du Code civil rapprochés. Aussi la Cour Royale de Paris, le 26 décembre de l'année dernière, a-t-elle réduit un legs fait à l'enfant légitime du fils naturel par l'aïeul qui, certes, en tant qu'aïeul, était aussi étranger pour le petit-fils naturel que le docteur, en tant qu'on peut l'être relativement à Ursule (BALZAC, 1944: 95).

Las referencias podrán seguir ampliándose a temas colaterales ${ }^{47}$. Ciertamente los principios individualistas inspiradores del Code civil jamás dejaron indiferente a BALZAC: Le Colonel Chabert (1832), Le Père Goriot (1835), Le Contrat de mariage (1835), Le Lys dans la vallée (1835), Le curé de village (1841)... Pero no quiero desviar a aquel entonces, sino ahora, a hoy, siquiera en addenda.

\footnotetext{
45 LÉONARD-ROQUES, 1999.

46 Vid. también MOREAU, 1887: 246-275.

47 Frappier-Mazur, 2001.
} 


\section{ADDENDA. DIDEROT Y LA PARADOJA DEL ESPECTADOR DISTRAÍDO}

La Historia — ioh, la Historia! — a la que tantos espectadores asisten distraídos...

El régimen jurídico de la filiación en Francia, inaugurado por el Code napoleónico en 1804, llegó a su fin con la promulgación de la Loi n. ${ }^{\circ}$ 72, du 3 janvier de 1972, sur la filiation ${ }^{48}$. No obstante, hubo aún que esperar a la Ordonnance $n^{\circ}{ }^{\circ} 2005-759$, du 4 juillet 2005 (JO du 6 juillet 2005), portant réforme de la filiation ${ }^{49}$, resultado de la habilitación dada al Gobierno por la Loi n. ${ }^{\circ} 2004-1343$, du 9 décembre 2004, de simplification du Droit ${ }^{50}$, en especial a través de su art. 4, para que la reforma efectivamente se trasladara a la letra del derecho positivo.

Sí, ciertamente, el patio de butacas del Gran Teatro de la Historia rebosa de espectadores distraídos...

DIDEROT, ha sido durante todo ese tiempo - doscientos un años de Historia...un transgresor, un avant-gardiste; sin duda, avant la lettre. Yo creo que también après la lettre...; ; tanto hablamos de igualdad!...

Sin embargo, la Historia es, al cabo, de los espectadores distraídos... Pero tal vez no descubra nada acerca de la Historia, y quizá tampoco sobre DiDEROT.

\section{REFERENCIAS BIBLIOGRÁFICAS}

ARmand, G., 2011: «Diderot ou le paradoxe sur la filiation», en Ch. CHELEBOURG, D. MARTENS y M. Watthée-Delmotte (eds.), 39-50.

ARnAUD, A.-J., 1969: Les origines doctrinales du Code civil français, Paris: LGDJ (1973); Essai d'analyse structurale du Code civil français. La règle du jeu dans la paix bourgeoise, Paris: LGDJ.

AugÉE, Ch., y Dorlhac, J., 1891: De la condition juridique des enfants naturels dans le passé, dans le présent, dans l'avenir. Étude de législation comparée, Paris: Librairie moderne de Droit et Jurisprudence Arthur Rousseau.

Auroux, S.; Bourel, D., y Porset, Ch. (eds.), 1991: L’Encyclopédie, Diderot, l'esthétique: mélanges en hommage à Jacques Chouillet: 1915-1990, Paris: Presses Universitaires de France.

BALCOU, J., 1973: «Un épisode de la guerre entre Diderot et Fréron: l'affaire du Fils naturel en 1757», Annales de Bretagne, 80, 3-4, 499-506.

BALZAC, H. DE, 1944: Ursula Mirouët, ed. de M. Allem, Paris: Garnier.

BARBARIN, R., 1960: La condition juridique du bâtard d'après la jurisprudence du Parlement de Paris, du concile de Trente à la Révolution française, Mayenne: Imp. Floch.

BAUDIN, M., 1932: Les Bâtards au théatre en France de la Renaissance à la fine du XVIIIe siècle, Baltimore: The Johns Hopkins Press.

48 En consulta de 28 de marzo de 2012, vid. http://www.legifrance.gouv.fr/affichTexte.do? cidTexte=JOR FTEXT000000875196.

${ }_{49}$ En consulta de 28 de marzo de 2012, vid. http://www.legifrance. gouv. fr/affichTexte.do? cidTexte=JORF TEXT000000451869EdateTexte $=$ EcategorieLien $=i d$.

${ }^{50}$ En consulta de 28 de marzo de 2012, vid. http://www.legifrance.gouv.fr/affichTexte.do?cidTexte=JOR FTEXT000000256180. 
BAUdRILlard, J., 1977: L'effet Beaubourg: implosion et dissuasion, Paris: Galilée.

- 1978: «La précession des simulacres», Traverses, 10, 3-37.

- 1987: Cultura y simulacro, trad. de P. Rovira, Barcelona: Kairós.

Bernard, C., y Schuerewegen, F. (eds.), 2011: Balzac, pater familias, Amsterdam/New Cork: Rodopi.

BLACHE, E., 1879: De la condition juridique des enfants naturels au point de vue du droit de famille dans le droit romain er dans le droit français ancien et moderne, Dijon: Imp. D. Carré.

BloqueT, J., 2012: «"La société n'a pas intérêt à ce que des bâtards soient reconnus” (Napoléon)», ambos La Revue Napoleonica, 2.14, 50-73.

BonneCASE, J., 1931: Introduction à l'étude du droit, Paris: Sirey (2.a ed.).

- 2000: Introducción al estudio del Derecho, trad. de J. Guerrero R., Bogotá: Temis.

CARBOnNIER, J., 1981: «Le Code Napoléon en tant que phénomène sociologique», Revue de la recherche juridique. Droit prospectif, 3, 327-336.

— 1986. «Le Code civil», en P. NorA (dir.), t. II, «La Nation», 293-315.

CARICIENTE BENACERRAF, J., 1951: De la condition juridique de l» enfant naturel simple en droit comparé, Paris: A Pedone.

Carlson, M., 1972: The French Stage in the Nineteenth Century, Metuchen: New Jersey, Scarecrow Press.

Chartier, P., 1997: «La loi du père: Étude de l'Entretien d'un père avec ses enfants (Ire partie)», Recherches sur Diderot et sur l'Encyclopédie, 23, 9-62.

- 1998: «La loi du père: étude de l'Entretien d'un père avec ses enfants (dernière partie)», Recherches sur Diderot et sur l'Encyclopédie, 24, 39-100.

Chelebourg, Ch.; Martens, D., y Watthée-Delmotte, M. (eds.). 2011: Héritage, filiation, transmission: configurations littéraires (XVIIIe-XXIe siècles), Louvain-La-Neuve: Presses universitaires de Louvain.

Connors, L. J., 2012: Dramatic battles in Eighteenth-century France: philosophes, anti-philosophes and polemical theatre, Oxford: Voltaire Foundation.

CoulON, H., 1887: De la condition des enfants naturels dans la succession de leurs père et mère, Paris: Marchal y Billard.

D’Alembert, Jean Le Rond dit., 1821-1822: Euvres complètes, Paris: A. Belin y Bossange père et fils y Bossange frères, vol. I, 9-12.

DABIN, J., 1965: Le statut juridique de l'enfant naturel, Bruxelles: Établissements É. Bruylant.

DAvies, S., 1991: «Réflexions sur le thème de la loi et la justice dans les œuvres de fiction de Diderot», en S. Auroux, D. Bourel y Ch. PORSET (eds.), 1991, 123-129.

Debord, G., 1967: La société du spectacle, Paris: Buchet-Chastel. La sociedad del espectáculo (1976), trad. de F. CASADO, Madrid: Miguel Castelote.

DictionnAIRE DE L'ACADÉmIE FRANÇOISE (Nouvelle édition), 1772: Lyon: Chez Benoit Duplain, père, Joséph Duplain, fils.

Diderot, D., 1969-1973: Euvres complètes, éd. Chronologique avec introduction de Roger LEWINTER, Paris: Le Club français du livre, vols. I-XV.

- 1975: Le fils naturel et Les entretiens su «Le fils naturel» (texte integral), avec une Notice biographique, une Notice historique et littéraire, un lexique, des Notes explicatives, des Documents, des Jugements, un questionnaire et des Sujets de devoirs par Jean-Pol Caput, Paris, Librairie Larousse.

- 1985: El sobrino de Rameau, ed. de C. Roig, trad. de D. Grimau, Madrid: Cátedra.

- 2008: El hijo natural. Conversaciones sobre «El hijo natural», ed. y trad. de F. LAFARGA, Madrid: Asociación de Directores de Escena de España. 
Diderot, D., y D’AlemberT, J. Le R., 1751-1765: Encyclopédie ou Dictionnaire raisonné des sciences, des arts et des métiers, vols. I-XVII.

Dieckmann, H., 1969: «The Transformation the Concept of Imitation in the French Aesthetics of the Eighteenth Century», en H. R. JAuss (Hrsg.), 28-59.

Edmiston, W. F., 1985: Diderot and the Family. A conflict of Nature and Law, Saratoga, Calif.: Anna Libri.

FABRE, J., 1961: «Deux frères ennemis: Diderot el Jean-Jacques», Diderot Studies, 3, 155-213.

FeIlla, C., 2013: The Sentimental Theatre of the French Revolution: Performing Virtue, Burlington, VT-London: Ashgate (en esp. «Revolutionary Tableaux: Diderot, David, and the Sentimental Frame of Politics»).

FELlows, O., 1981: «The facets of illegitimacy in the French Enlightenment», Diderot Studies, 20, 77-97.

FENET, P.-A., 1827-1828: Recueil complet des travaux préparatoires du Code civil, suivi d'une édition de ce code: suivi d'une édition de ce code, a laquelle sont ajoutés les lois, décrets et ordonnances formant le complément de la législation civile de la France, Paris: Imprimiere de Marchand Breuil, vols. I-XV.

FIORE, Q., 1967: The Medium is the Message: An Inventory of Effects, New York: Bantam.

Fontaine, H.-E.-E. (1881): De la condition civile de l'enfant naturel à Rome et en France, Paris: Alphonse Derenne.

FOWLER, J. E., 2000: Voicing desire. Family and sexuality in Diderot's narrative, Oxford: Voltaire Foundation.

FrantZ, P., 1998: L’Esthétique du tableau dans le théâtre du XVIIIe siècle, Paris: Presses Universitaires de France.

FrapPIER-MAZUR, L., 2001: «Max et les chevaliers. Famille, filiation et confrérie dans La Rabouilleuse», en C. BERNARD y F. SCHUEREWEGEN (eds.), 51-61.

Fried, M., 1980: Absorption and Theatricality: Painting and Beholder in the Age of Diderot, Berkeley: University of California Press.

GaIfFe, F. A., 1910: Le drame en France au XVIIIème siècle, Paris: Armand Colin.

GERBER, M., 2005: «Illegitimacy, Natural Law, and Legal Culture on the Eve of the French Revolution», Proceedings of the Western Society for French History (University of Michigan), 33, 240-257.

Goldoni, Ch., 1758: Le Véritable ami, comédie en 3 actes et en prose, traduite de l'italien en français, par M. l'abbe**, Avignon, Liège (el lugar y editor real es Paris, M. Lambert).

GolzINK, J., 2000: «Dramaturgies du Droit. Le Fils naturel et Le Mariage de Figaro», en Ch. BIET (comp.), Droit et littérature sous l'Ancien régime: le jeu de la valeur et de la loi, Paris: Honoré Champion, 259-271.

Harth, D., y Raether, M. (Hrsg.), 1987: Denis Diderot, oder, Die Ambivalenz der Aufklärung, Heidelberger Vortragsreihe zum Internationalen Diderot-Jahr 1984, Würzburg: Königshausen/Neumann.

Hays, M., 1981: The Public and Performance: Essays in the History of French and German Theater, 1871-1900, Ann Arbor: Michigan UP.

Heartz, D., 1989: «Locatelli and the Pantomime of the Violinist in Le Neveu de Rameau», Diderot Studies, 27, 115-127.

HunT, L., 1994: The Family Romance of French Revolution, Berkeley: University of California Press.

IDA, H., 1999: «La “pantomime” selon Diderot. Le geste et la démonstration morale», Recherches sur Diderot et sur l'Encyclopédie, 27, 25-42. 
JAuss, H. R. (Hrsg.), 1969: Nachabmung und Illusion. Kolloquium Giessen Juni 1963 Vorlagen und Verbandlungen, München: Wilhelm Fink.

- 1969: «Nachahmungsprinzip und Wirklichkeitsbegriff in der Théorie des Romans von Diderot bis Stendhal», en H. R. Jauss (Hrsg.), 157-178.

LÉONARD-RoQues, V., 1999: «Antony d'Alexandre Dumas ou les ambiguïtés d'une réhabilitation romantique de la figure du bâtard», en J. SESSA (dir.), 283-295.

LEWINTER, R., 1966. «L'exaltation de la vertu dans le théâtre de DiDEROT», Diderot Studies, 8, 119-169.

Lough, J., 1972 (1957): Paris Theatre Audiences in the Seventeenth and Eighteenth Centuries, Oxford: Oxford UP.

Lagrave, H., 1972: Le théâtre et le public à Paris de 1715 a 1750, Paris: Klincksieck.

MAUZI, R., 1960: L'idée di bonheur dans la littérature et la pensée française au XVIIIe siècle, Paris: Armand Colin.

- 1961: «Les rapports du bonheur et de la vertu dans l'oeuvre de Diderot», Cabiers de l'Association internationale des études francaises, 13, 255-268.

McLuhan, M., 1964: Understanding Media: The Extensions of Man, New York: Mentor.

MCLuhan, M., y FiORE, Q., 1967: The medium is the message: An inventory of effects, New York: Bantam.

MéLÈSE, P., 1934: Le théâtre et le public à Paris sous Louis XIV (1659-1715), Paris: Droz.

MÉnIL, A., 1995: Diderot et le drama. Théâtre et politique, Paris: Presses universitaires de France.

MitTman, B., 1984: Spectators on the Paris Stage in the Seventeenth and Eighteenth Centuries, Ann Arbor: Michigan UP.

Moreau, F., 1887: Le code civil et le théâtre contemporain: M. Alexandre Dumas, fils, Paris: L. Larose et Dorcel (en esp. «La filiaton naturel»).

MORTIER, R., 1997: «Diderot et la fonction du geste», Recherches sur Diderot et sur l'Encyclopédie, 23, 79-87.

NorA, P. (dir.), 1986: Les Lieux de la mémoire, Paris: Gallimard.

PuCCI, S. R., 2004: «Picture Perfect: Snapshots of the Family», en L'Esprit Créateur, 44, 1, 68-82.

PufERndor, S., 1984: De jure naturae et gentium (1672), Lib. II, Cap. 3, «De la ley natural en general», trad. de A. GARCíA-GALLO, 1984. Manual de Historia del Derecho español. II: Metodología histórico-jurídica. Antología de fuentes del derecho español, Madrid: Artes Gráficas y Ediciones, 10. ${ }^{a}$ reimp.

RAETHER, M., 1987: «Pantomime und Mimesis: die interpretation des Neveu», en D. HarTH y M. RAETHER (Hrsg.), 104-125.

Ravel, J. S., 1993: «Seating the Public: Spheres and Loathing in the Paris Theaters, 1777-1788», French Historical Studies, 18.1, 173-210.

- 1999: The Contested Parterre: Public Theater and French Political Culture, 1680-1791, Ithaca: Cornell UP.

Regnault, H., 1922: La condition juridique du bâtard au Moyen-Age, Pont-Audemer: Imp. Lescuyer Frères.

ROBERT, M., 1972: Roman des origines et origines du roman, Paris: Editions Bernard Grasset.

- 1973: Novela de los orígenes y orígenes de la novela, trad. de R. Durbán SÁnCHEZ, Madrid: Taurus.

Rousseau, J.-J., 1997: Las confesiones, trad., prólogo y notas de M. Armiño, Madrid: Alianza Editorial.

RICHARD, L., 1866: De la condition juridique des enfants naturels en droit romain et droit français, Caen: Himmais. 
SAADA, L., 2012: «Les interventions de Napoléon Bonaparte au Conseil d'État sur les questions familiales», La Revue Napoleonica, 2.14, 25-49.

SAVATIER, J., 1965: L'évolution de la condition juridique des enfants naturels en droit français, Bruxelles: Établissements É. Bruylant.

SESSA, J. (dir.), 1999: Figures de l'exclu. Actes du colloque international den littérature comparée (2-3-4 mai 1997), Saint-Étienne: Publications de l'Université Jean-Monnet.

SimON, J., 2001: Beyond Contractual Morality. Ethics, Law, and Literature in Eighteenth-Century France, Rochester, New York: University of Rochester Press (en esp. «Negotiating the Legal and Morak: Diderot Conversation of a Father with His Children»).

Stenger, G., 2013: Diderot: Le combattant de la liberté, Paris: Éditions Perrin.

SzONDI, P., 1979: «Tableau et coup de théâtre. Pour une sociologie de la tragédie domestique et bourgeoise chez Diderot et Lessing», Poétique, 9, 1-14.

VAN HONSTÉ, V., 1977: La condition juridique des enfants naturels: passé, présent et avenir. Mercuriale prononcé par... à l'audience solennelle de rentrée de la Cour d'Appel de Bruxelles, le $1^{\text {er }}$ sept. 1977, Bruxelles: Cour d'Appel de Bruxelles.

Vargas Llosa, M., 2008: «La civilización del espectáculo», El País, 6 de septiembre.

— febrero 2009: «La civilización del espectáculo», Letras Libres, 6-14.

- 2012: La civilización del espectáculo, Madrid: Alfaguara. 